\title{
GAIA Level 4 Major External Structural Defect
}

National Cancer Institute

\section{Source}

National Cancer Institute. GAlA Level 4 Major External Structural Defect. NCI Thesaurus.

Code C127960.

GAIA Level 4 Major External Structural Defect is defined by four criteria: first, the defects are of a prenatal origin; second, at least one of the following requirements must be met:

a) Alterations in the external anatomy that are present and visible at the time of live birth, and that persist beyond the immediate peripartum period unless surgically repaired OR b) Alterations in the external anatomy that are present and visible in a stillbirth or in the products of conception of a spontaneous or therapeutic abortion; third, the defect(s) affect (or have the propensity to affect) the health, survival, or physical or cog nitive functioning of the individual; fourth, at least one of the following requirements must be met: a) Confirmation by medical record review; OR b) Confirmed in claims data (ICD9/ICD-10 diagnoses). 